\title{
The Visitor Perceptions on Whale-watching Tours based on Mirissa, Sri Lanka
}

\author{
Prakash T.G.S.L.*, Perera P.K.P., Amarasinghe N.S. \\ Department of Forestry \& Environmental Science, University of Sri Jayewardenepura, Sri Lanka \\ *prakashtgsl@gmail.com
}

\begin{abstract}
Whale-watching is one of the fastest-growing sectors of wildlife tourism in the world. The waters off Sri Lanka have been identified as important habitats for Blue whales (Balaenoptera musculus); a species listed as Endangered in the IUCN Red List of Threatened Species. Coastal destinations of Mirissa in the south-west, Trincomalee in the north-east and Kalpitiya on the west coast have emerged as popular places for whale watching, especially among foreigners. However, unregulated boat-based tourism and related visitor disturbance on cetacean populations inhabiting these waters has now become a serious concern. Social media at present is playing an important role as major information sources for travelers. Amidst the social-media websites that contain travel-related content, TripAdvisor is considered to be the most popular as it provides a social interaction platform for travelers to share their experiences about a visit to a certain destination. These reviews serve as reliable and unbiased information for contemporary travel researchers. As such, this study attempted to explore the positive and negative attributes of the whale watching industry in Mirissa, Southern Province of Sri Lanka. Content-analysis of a total of 131 reviews posted in TripAdvisor during the period from $01^{\text {st }}$ January 2015 to $31^{\text {st }}$ December 2016 found five positive attributes and four negative attributes associated with the whale watching industry in Mirissa. Probability of encountering good numbers of whales, quality of the services offered by boat operators, crew performance, tour organization, and the efforts taken by relevant stakeholders to conserve whales were the positive attributes revealed by the analysis. The negative attributes associated with whale-watching industry included the discrepancies in prices, duration of the tour, distance maintained during whale watching (boats getting too close to whales), and number of passengers per vessel (overcrowding).Visitors were moderately concerned on the size and quality of the vessels. It was revealed that 10 out of 11 attributes highlighted by the visitors are tour-operator related aspects, and this calls for an overall improvement of the tour operator standards in the whale-watching industry. Impetus for sustainable marine reserve management to assure better visitor experiences are further discussed.
\end{abstract}

Keywords: Indian ocean, Marine mammals, Sri Lanka, Ecotourism, Whale watching, Cetaceans 